\title{
Isolating intact phytoplasma particles from plants for sequencing applications and for testing host responses to phytoplasma
}

\author{
Nofar Assoline ${ }^{1}$, Diego Santos-Garcia², Vered Naor ${ }^{3}$, Ofir Bahar $^{1}$ \\ ${ }^{1}$ Department of Plant Pathology and Weed Research, Agricultural Research Organization - Volcani Centre, \\ Rishon LeZion, Israel \\ ${ }^{2}$ Department of Entomology, The Robert H. Smith Faculty of Agriculture, Food and Environment, The Hebrew \\ University of Jerusalem, Rehovot, Israel \\ ${ }^{3}$ Shamir Research Institute, Katzrin, Israel
}

\begin{abstract}
Candidatus Phytoplasma are obligate plant parasites limited to the phloem tissue. The inability to grow phytoplasma in artificial culture seriously impedes the study of these important prokaryotes. In this study, we optimized a protocol to purify intact phytoplasma particles from infected periwinkle plants using filtering, differential and density gradient centrifugations. We then used confocal and transmission electron microscopy to visualize intact phytoplasma particles in the preparation. Quantitative-PCR and DNA-seq analyses revealed that phytoplasma DNA was significantly enriched following the purification procedure. The extractions containing intact phytoplasma cells were used to challenge periwinkle plants using a newly developed inoculation method and the expression level of two defence-related genes was monitored. Both genes were upregulated in response to phytoplasma enriched preparations, and to a lesser extent to preparations from healthy plants. This procedure allows for both phytoplasma DNA enrichment from mixed samples and for purifying intact phytoplasma particles that can be used to further examine host responses to phytoplasma.
\end{abstract}

Key words : phytoplasma, DNA enrichment, sequencing ,microscopy.

\section{Introduction}

Candidatus Phytoplasma (phytoplasma) are obligate, plant-pathogenic mollicutes. Unlike most bacterial pathogens, which colonizes the intercellular spaces of the plant tissue, these bacteria are strictly restricted to the phloem tissue, to which they are delivered by specialized insect vectors.

Very little is known on host responses to phytoplasma infection and even more on phytoplasma perception by the plant immune system. The inability to cultivate phytoplasma in vitro, and to perform artificial inoculations with pure culture, clearly imped such studies. This inability also reflects on genomic studies of phytoplasma, for which phytoplasma DNA have to be obtained from mixed samples. To overcome the scarce amounts of phytoplasma DNA in mixed samples, methods were developed to separate host DNA from phytoplasma DNA by means of $\mathrm{CsCl}$ gradient centrifugation
(Kirkpatrick et al. 1987), by phytoplasma DNA enrichment using suppression subtractive hybridization (Cimerman et al. 2006) and by phytoplasma particles isolation (Jiang and Chen 1987). In this study we developed a procedure for phytoplasma particle enrichment from infected plant tissue. We used the enriched preparation to obtain higher amounts of phytoplasma DNA for genome sequencing and also to test host plant response to phytoplasma particles.

\section{Materials and methods}

Sixty-five grams of stolbur-infected periwinkle tissue was grinded with $200 \mathrm{ml}$ of phytoplasma extraction buffer $(20 \mathrm{mM}$ potassium-phosphate PH-7.4, sucrose, fructose, calcium nitrate, magnesium chloride, BSA and polyvinylpyrrolidone) using a Waring blender. The homogenate was passed through 3 layers of cheese cloth and then centrifuged for $15 \mathrm{~min}$ at $2000 \times \mathrm{g}\left(4^{\circ} \mathrm{C}\right)$ to discard remaining plant tissue 
and cell debris. The supernatant was collected and centrifuged for $30 \mathrm{~min}$ at $22,000 \times \mathrm{g}\left(4^{\circ} \mathrm{C}\right)$ to pellet phytoplasma particles. The pellet was resuspended with extraction buffer and loaded onto an Optiprep density gradient column and centrifuged for $20 \mathrm{~min}$ at $20,000 \mathrm{x} \mathrm{g}\left(4^{\circ} \mathrm{C}\right)$. The clear middle fraction was collected and subjected to another, identical round of gradient centrifugation after which the middle fraction was collected, diluted with extraction buffer and pelleted for $1 \mathrm{~h}$ at $100,000 \times \mathrm{g}\left(4^{\circ} \mathrm{C}\right)$. The final pellet was resuspended with $2 \mathrm{ml}$ of $1 \mathrm{X}$ PBS and filtered $(0.45 \mu \mathrm{M})$. Control sample included the same procedure with a phytoplasma-free periwinkle plant.

We used the CTAB method to purify DNA from both samples (Mawassi et al. 2018). Then the relative the DNA ratio of host/phytoplasma was measured by a quantitative-PCR (qPCR) approach using periwinkle and phytoplasma specific primers. Samples that were found to be enriched with phytoplasma DNA were sent for Illumina sequencing using MiSeq (2x250bp). Reads obtained were quality filtered with Trimmomatic and then classified with Kraken 2 using a custom database including all the RefSeq complete bacterial genomes, the Peanut witches'broom phytoplasma NTU2011 (GCA_000364425.1), and the periwinkle nuclear and chloroplast

genomes (GCA_000949345.1 and NC_021423

, respectively).

In-vitro grown periwinkle plants were challenge with phytoplasma enriched samples using a new cotton wool clip-inoculation method. Then, leaf samples were collected at 6,24 and $48 \mathrm{~h}$ post inoculation for RNA extraction followed by cDNA synthesis and qPCR with periwinkle primers to estimate the expression level of host defense-related gene.
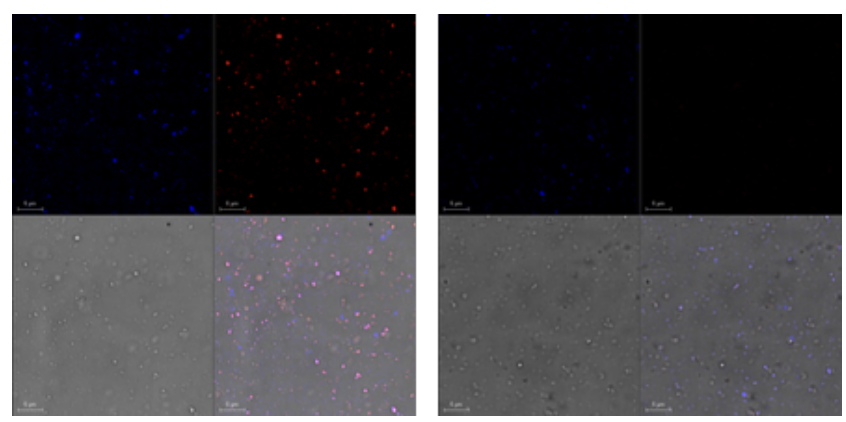

Figure 1. Confocal microscopy observation of phytoplasma enriched samples purified from infected and healthy periwinkle plants. Samples were dyed with DAPI for nucleic acids (upper left in each panel) and FM4-46 for membranes (upper right in each panel). Merged image is at the bottom right of each panel. Left and right panels represent preparations from infected and healthy plants, respectively.

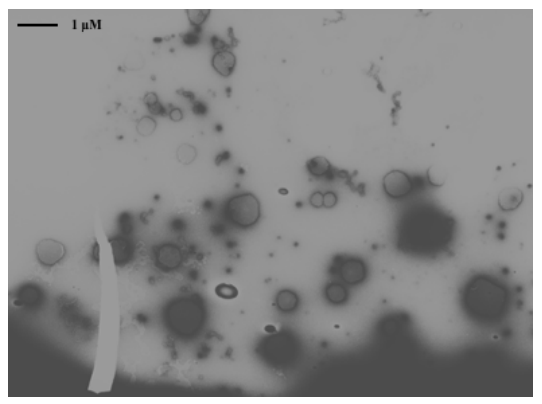

Figure 2. TEM image of a phytoplasma-enriched sample purified from a periwinkle plant.

\section{Results}

Phytoplasma DNA was detected in all the phytoplasma-enriched samples using qPCR. To test whether phytoplasma DNA was enriched in comparison with standard total DNA extraction from periwinkle, we conducted qPCR using phytoplasma and periwinkle primers and calculated the $\Delta \mathrm{Ct}$ of the two PCR amplicons in the two samples. The enriched sample had a $\Delta \mathrm{Ct}$ value of 7 , indicating that the phytoplasma DNA concentration $v s$. the plant DNA concentration was $\sim 100$ fold higher in the enriched sample. Illumina sequencing of one enriched sample and one total DNA sample revealed $\sim 20$-fold increase in phytoplasma reads in the enriched sample.

We used confocal microscopy with membrane and DNA dyes to test the presence of intact phytoplasma particles in the sample. Particles at the size range of phytoplasma cells were stained 
with both red (staining membrane) and purple (staining DNA) dyes, suggesting cells remained intact (co-localizing dyes). None of the dyes reacted with the negative control samples (Fig. 1). Intact phytoplasma-like particles were also observed by TEM visualisation of the enriched sample, while none were detected in the unenriched sample (Fig. 2).

\section{Discussion}

Phytoplasma diseases are difficult to study in comparison with their culturable bacterial counterparts. The ability to obtain a pure culture of the disease agent is paramount to every phytopathological study. As phytoplasma cannot be cultivated in vitro, alternative approaches have to be developed to allow a more thorough study of these important plant pathogens.

In this study we have optimized a method to purify intact phytoplasma particles from infected plants. This purification allowed for obtaining a significantly higher phytoplasma DNA content as compared with total DNA extraction methods. Furthermore, it yielded approximately 20-fold enrichment in phytoplasma reads with Ilumina sequencing, showing the applicability of this procedure for whole genome sequencing of phytoplasma.

Very little is known on host responses to phytoplasma infections. Obtaining intact phytoplasma particles allowed us to artificially "inoculate" plants and to test their response to phytoplasma particle. Immune-related genes were upregulated in response to phytoplasma suggesting that plants are capable of detecting phytoplasma infections. Which parts of phytoplasma are exactly detected is not yet clear nor is which immune genes are responsible for this response. Further studies, using this purification method, are underway to address these questions.

\section{Acknowledgements}

Time New Roman 10, Time New Roman 10, Time New Roman 10, Time New Roman 10,
Time New Roman 10, Time New Roman 10,Time New Roman 10.

\section{References}

Kirkpatrick BC, Stenger DC, Morris TJ, and Purcell AH 1987. Cloning and detection of DNA from a nonculturable plant pathogenic mycoplasma-like organism. Science, 238: 197-200.

Cimerman A, Arnaud G, and Foissac X 2006. Stolbur phytoplasma genome survey achieved using a suppression subtractive hybridization approach with high specificity. Applied and Environtal Microbiology, 72: 3274-3283.

Jiang YP, and Chen TA 1987. Purification of mycoplasma-like organisms from lettuce with aster yellows disease. Phytopathology, 77: 949-953.

Mawassi M, Dror O, Bar-Joseph M, Piasetzky A, Sjölund J, Levitzky N, et al. 2018. "Candidatus Liberibacter solanacearum" is tightly associated with carrot yellows symptoms in Israel and transmitted by the prevalent psyllid vector Bactericera trigonica. Phytopathology 108: $1056-1066$. 